\title{
GÊNERO, SEXUALIDADE E FORMAÇÃO DE PROFESSORES: UMA ANÁLISE A PARTIR DA PRODUÇÃO ACADÊMICA DA ANPED ${ }^{1}$
}

\author{
Maria CláUdia Dal'IGna \\ Renata Porcher Scherer \\ ÉderSON DA CRUZ \\ Universidade do Vale do Rio dos Sinos (UNISINOS), Porto Alegre, \\ Rio Grande do Sul, Brasil
}

\begin{abstract}
REsumo: Este artigo apresenta e discute os resultados de uma análise realizada a partir da produção acadêmica de uma importante associação de pesquisa em educação do Brasil, a ANPEd, desenvolvida por pesquisadoras e pesquisadores vinculados ao GT 23: Gênero, Sexualidade e Educação. Tal análise foi elaborada para subsidiar pesquisas vinculadas a um Programa de Pós-Graduação em Educação. A partir dessa produção, tomando como referencial teórico os Estudos de Gênero e os Estudos Foucaultianos, o presente artigo examina 25 trabalhos apresentados em reuniões anuais, entre 2004 e 2014. Essa análise possibilita refletir sobre os modos como gênero e sexualidade são abordados ao focalizar a formação de professores, e oferece contribuições para que se possa construir e delimitar futuros problemas de pesquisa sobre esses temas.
\end{abstract}

PalavRas-chave: Gênero. Sexualidade. Formação de professores. ANPEd. 
A análise que está sendo aqui apresentada é desenvolvida a partir de uma revisão bibliográfica, tal como compreende Alda Alves-Mazzotti (1998), pois pretende organizar uma certa produção acadêmica, tentando identificar as dimensões que vêm sendo destacadas e privilegiadas, e aquelas que ainda merecem ser investigadas.

Assim, este artigo apresenta e discute os resultados de uma análise realizada a partir da produção acadêmica da Associação Nacional de Pesquisadores em Educação (ANPEd), que se constitui como uma importante associação de pesquisa em educação do Brasil, especialmente aquela desenvolvida por pesquisadoras e pesquisadores ${ }^{2}$ vinculados ao Grupo de Trabalho 23 (GT 23): Gênero, Sexualidade e Educação.

O corpus de análise foi constituído por 25 trabalhos que articulam gênero e/ou sexualidade ao focalizar a formação de professores e professoras, todos apresentados no GT 23 no período de 2004 a 2014. A análise desse corpus foi elaborada para subsidiar um conjunto de pesquisas realizadas na região Sul do Brasil, vinculadas a um Programa de Pós-Graduação em Educação. Atualmente, duas pesquisas de doutorado, dois trabalhos de conclusão de curso e um projeto de pesquisa mais amplo que reúne estes estudos $^{3}$ têm se servido da analítica desenvolvida sobre a produção acadêmica do GT 23 da ANPEd, para construir e delimitar seus problemas. Ao mesmo tempo, a sistematização e a análise dessa produção acadêmica sobre gênero, sexualidade e formação de professores podem fornecer subsídios necessários para que outras possibilidades e desdobramentos de pesquisas envolvendo tais temáticas possam ser produzidas, tanto no espaço do programa da pósgraduação a que essas cinco pesquisas se vinculam, como também para que seus resultados possam potencializar outras pesquisas afins.

Tanto as pesquisas referidas como o presente artigo assumem como referencial teórico os Estudos de Gênero e os Estudos Foucaultianos. De modo mais específico, assumimos três pressupostos teórico-metodológicos que irão guiar nossas análises, com base nas contribuições da pesquisadora Dagmar E. Meyer (2012):

Primeiro. A linguagem ocupa centralidade para a significação do mundo, uma vez que não é compreendida como mero instrumento neutro de comunicação com o exterior, ou como espelho da realidade, mas como uma construção social, histórica e cultural que institui formas de ser e de viver e dar significado à realidade. ${ }^{4}$ 
Segundo. A educação, em um sentido mais amplo, é aqui compreendida como conjunto de processos pelos quais indivíduos são transformados ou se transformam em sujeitos de uma cultura, o que significa, no âmbito dessa análise, assumir uma postura segundo a qual tais processos não são formativos apenas a partir daquilo que se elegeu importante ensinar, mas que, num sentido mais amplo, também formam através daquilo que é posto à margem do ensino, instituindo marcas, lugares e posições nos jogos de poder. ${ }^{5}$

Terceiro. O gênero funciona como organizador do social e da cultura, e de tal forma, assim como já anunciaram autoras como Joan Scott (1995) e Linda Nicholson (2000), constitui-se um elemento importante a ser considerado para análise, não disperso da constituição histórica dos sujeitos e das culturas e como uma forma primária de significar as relações de poder.

Considerando esses três pressupostos teórico-metodológicos, pode-se afirmar que esse trabalho assume um compromisso em descrever e problematizar os processos pelos quais significados da produção acadêmica sobre gênero, sexualidade e formação de professores são produzidos, a partir de complexas redes de saber e de poder, e que esses processos produzem consequências para os indivíduos e/ou grupos aos quais eles se dirigem. Assim, ao optar por trabalhos acadêmicos como superfície analítica, compreendemos que eles podem nos auxiliar a compreender as formas pelas quais as relações de gênero e sexualidades podem ser vividas pelos indivíduos em diferentes momentos da sua vida. Trata-se de um emaranhado de fios que constituem complexas teias discursivas, que não apenas descrevem, mas que conformam os modos de compreender, também, as relações de gênero e as sexualidades, em articulação com a formação de professores, objetos dessa análise.

Debruçando-se sobre tais pressupostos teórico-metodológicos, este trabalho busca fomentar um debate sobre o que tem sido dito acerca da formação de professores, e que atravessamentos de gênero e de sexualidade são possíveis de serem identificados (ou não) nas pesquisas desenvolvidas pelo GT 23.

Para desenvolver nossa argumentação, estruturamos a discussão a seguir em duas seções: na primeira, $A$ produção acadêmica da ANPEd em contexto, explicamos de que modos a análise proposta neste artigo foi organizada e desenvolvida, e apresentamos a justificativa para a escolha dos trabalhos e a definição da temporalidade examinada; na segunda, Gênero, sexualidade e formação de professores em debate na pesquisa educacional, apresentamos o material empírico analisado neste artigo e discutimos os 
modos como gênero e sexualidade são abordados ao focalizar a formação de professores; na terceira e última seção, após a explanação desses resultados, apresentamos, então, as conclusões advindas da análise de parte da produção acadêmica do GT 23 da ANPEd sobre os temas gênero, sexualidade e formação de professores.

\section{A PRODUÇÃO ACADÊMICA DA ANPED EM CONTEXTO}

O processo metodológico que nos propusemos a realizar deu-se, inicialmente, pela tentativa de mapear a produção acadêmica brasileira sobre formação de professores, articulada às relações de gênero e às sexualidades. Fizemos isso em alguns bancos de dados reconhecidos na área educacional, e dentre eles destacamos o que chamamos de banco de dados sistematizado da produção acadêmica da ANPEd, disponível em formato digital no portal da Associação. ${ }^{6}$

Em 1978, a ANPEd realizou na Universidade Federal do Ceará sua primeira reunião científica nacional. E, desde 2000 , a partir da $23^{a}$ reunião, a ANPEd disponibiliza uma versão completa de cada trabalho e pôster apresentado nos grupos de trabalho, nas reuniões científicas nacionais. Considerando essas características do banco de dados da Associação, empreendemos uma primeira busca usando como palavras-chave os termos gênero, sexualidade e formação de professores, em relação. Essa busca nos direcionou para a produção acadêmica apresentada nos grupos de trabalho Formação de Professores (GT 08), Educação Fundamental (GT 13) e Gênero, Sexualidade e Educação (GT 23).

Nesse primeiro levantamento de informações sobre a produção acadêmica, identificamos 615 trabalhos publicados nos referidos grupos no período de 2004 a 2014. Todos os 615 trabalhos foram examinados por nós e, a partir dessa triagem, foi verificado que apenas 26 trabalhos buscavam realizar uma articulação entre os temas aos quais nos propomos investigar. Desses 26 trabalhos, 25 foram publicados no GT Gênero, Sexualidade e Educação e apenas um no GT Formação de Professores.

Em 2004, o Grupo de Estudos (GE) 23 Gênero, Sexualidade e Educação é criado (ainda como grupo de estudos, consolidando-se como grupo de trabalho dois anos após, em 2006), e parte da produção acadêmica dirigida às relações de gênero e sexualidades, antes diluída em outros grupos de trabalho, passa a ser apresentada sistematicamente neste grupo. Em 2014, nós (autoras e autor deste artigo), realizamos um primeiro exercício analítico ${ }^{7}$ deste corpus e o apresentamos em uma reunião regional no eixo temático 
Gênero, Sexualidade e Educação. Com isso, justificamos a temporalidade estabelecida (2004 a 2014) e o conjunto de trabalhos analisados (25).

Esse primeiro movimento já tornou possível inferir que os trabalhos que optam por olhar para a formação de professores de forma articulada aos conceitos de gênero e/ou sexualidade têm se concentrado, nos últimos dez anos, no GT 23 Gênero, Sexualidade e Educação, e que tal articulação não tem sido enfatizada no GT 08 Formação de Professores. Por isso, escolhemos lançar nosso olhar para a produção desse grupo de trabalho, para podermos descrever os modos como percebemos que gênero e sexualidade são abordados nos trabalhos analisados, ao focalizarem a formação de professores.

Além disso, é importante e necessário neste momento registrar que o estudo da produção acadêmica do GT 23 Gênero, Sexualidade e Educação já foi realizado por outras autoras e autores, em ocasiões distintas, por pesquisadoras e pesquisadores que compõe o GT. Ressaltamos aqui os seguintes estudos: Cláudia Ribeiro, Dagmar Meyer e Paulo Ribeiro (2004); Guacira Louro (2006); Márcia Ferreira e Georgina Nunes (2010); Cláudia Ribeiro e Constantina Xavier Filha (2013); Márcia Ferreira (2015); Márcia Ferreira e Márcia Coronel (2017).

Trabalho encomendado. Cláudia M. Ribeiro (UFLA); Dagmar E. Meyer (UFRGS); Paulo R. M. Ribeiro (UNESP/Araraquara).Título:"Gênero, sexualidade e educação:'olhares' sobre algumas das perspectivas teórico-metodológicas que instituem um novo GE." Apresentado na 27ª Reunião Anual da ANPEd, realizada em 2004.

Trabalho encomendado. Guacira L. Louro (UFRGS). Título: "Gênero, Sexualidade e Educação - das afinidades políticas às tensões teóricometodológicas." Apresentado na 29a Reunião Anual da ANPEd, realizada em 2006.

Comunicação de Pesquisa. Márcia Ondina V. Ferreira (UFPel); Georgina H. L. Nunes (UFPel). Título:"Panorama da produção sobre gênero e sexualidades apresentada nas reuniões da ANPEd (2000-2006)". Apresentada na 33a Reunião Anual da ANPEd, realizada em 2010.

Trabalho encomendado. Cláudia M. Ribeiro (UFLA); Constantina Xavier Filha (UFMS).Título: "Trajetórias teórico-metodológicas em 10 anos de produção do GT 23". Apresentado na 36a Reunião Anual da ANPEd, realizada em 2013.

Comunicação de Pesquisa. Márcia Ondina V. Ferreira (UFPel). Título: "O campo do gênero na ANPEd: hipóteses em construção." Apresentada na 37a Reunião Anual da ANPEd, realizada em 2015.

Artigo publicado em periódico. Márcia Ondina V. Ferreira (UFPel); Márcia C. V. K. Coronel (UFPel). Título: "Sobre a legitimação do campo do 
gênero na ANPEd." Publicado na revista Educação e Pesquisa, v. 43, n. 3, p. 815-831, jul./set., 2017.

Considerando os objetivos propostos para este artigo e sua limitada extensão, optamos por não detalhar as conclusões desses estudos. Apesar disso, consideramos importante citar cada um porque juntos eles compõem uma consistente fotografia da produção acadêmica do GT 23 Gênero, Sexualidade e Educação, e destacam as diferentes abordagens teóricas e metodológicas que sustentam essa produção, os grupos de pesquisa que estão radicados no GT, as disputas conceituais que têm se estabelecido e as afinidades políticas que mobilizam o grupo de pesquisadoras e pesquisadores. Os resultados apontam, ainda, desafios relacionados à visibilidade e à legitimação das relações de gênero e das sexualidades na ANPEd e no próprio GT 23. Por fim, um estudo detalhado desta produção nos mostrou que uma análise como esta proposta por nós, neste artigo, ainda se faz necessária porque a produção acadêmica do GT não foi examinada focalizando a formação de professores, como estamos buscando fazer.

Tendo feito esse parêntese, a seguir apresentamos uma distribuição temporal dos trabalhos encontrados no GT 23 Gênero, Sexualidade e Educação:

Tabela 1 - Total de trabalhos apresentados e selecionados para análise.

\begin{tabular}{|ccc|}
\hline Ano & $\begin{array}{c}\text { Número de trabalhos } \\
\text { apresentados }\end{array}$ & $\begin{array}{c}\text { Trabalhos selecionados, a partir das } \\
\text { temáticas investigadas }\end{array}$ \\
\hline 2004 & 13 & 1 \\
\hline 2005 & 13 & 1 \\
\hline 2006 & 12 & 0 \\
\hline 2007 & 16 & 4 \\
\hline 2008 & 11 & 2 \\
\hline 2009 & 12 & 1 \\
\hline 2010 & 15 & 3 \\
\hline 2011 & 15 & 2 \\
\hline 2012 & 17 & 3 \\
\hline 2013 & 17 & 5 \\
\hline 2014 & 26 & 3 \\
\hline
\end{tabular}

Fonte: Tabela elaborada pelas autoras e pelo autor (2017). 
Ao olharmos com atenção a tabela, podemos identificar que a produção do GT, voltada para a discussão sobre formação de professores, mesmo sendo pequena, tem se mantido constante. Apenas em 2006 não se teve nenhuma produção sobre formação de professores e, nos demais anos, teve-se, em média, de um a cinco trabalhos produzidos/apresentados. A leitura desses 25 trabalhos selecionados possibilitou elencarmos três unidades de sentido, denominadas: (1) Feminização do magistério e constituição da docência; (2) Diferenças de gênero e de sexualidade na formação de professores; (3) Gênero e sexualidade em foco na formação de professores. Temporalmente, dividimos essas unidades da seguinte forma:

Tabela 2 - Unidades de sentido criadas a partir dos trabalhos selecionados.

\begin{tabular}{|c|c|c|c|c|c|c|c|c|c|c|c|c|}
\hline $\begin{array}{l}\text { Unidade de } \\
\text { análise }\end{array}$ & $\frac{4}{\pi}$ & $\stackrel{m}{\sim}$ & ָั & $\bar{ָ}$ & 웅 & ঃั & $\stackrel{\infty}{\circ}$ & ¿্̀ & ๕ & ๕̊ & ষ্ণ & ङ艹 \\
\hline (1) & 0 & 0 & 1 & 0 & 1 & 0 & 0 & 2 & 0 & 0 & 1 & 5 \\
\hline (2) & 3 & 2 & 1 & 1 & 0 & 0 & 2 & 0 & 0 & 1 & 0 & 10 \\
\hline (3) & 0 & 3 & 1 & 1 & 2 & 1 & 0 & 2 & 0 & 0 & 0 & 10 \\
\hline
\end{tabular}

Fonte: Tabela elaborada pelas autoras e pelo autor (2017).

A tabela nos mostra um número menor de trabalhos relacionados à primeira categoria, enquanto, na segunda e na terceira categorias, percebese um aumento significativo no número de trabalhos apresentados. Outro fator temporal que nos chama atenção refere-se ao fato de que os trabalhos relacionados à primeira categoria que elencamos somente surgiram a partir de 2007, demonstrando o percurso de amadurecimento e de ampliação de discussões pelo qual o GT veio passando desde sua criação, em 2004. Também consideramos importante refletir - brevemente - que o aumento, a diminuição ou até mesmo a inexistência de determinadas discussões e temáticas nos trabalhos apresentados no GT podem ser fatores que estão articulados ao surgimento (ou não) de determinadas condições de possibilidade para que tais temas viessem a emergir, com maior ou menor ênfase, e que fossem abordadas tais temáticas e não outras. Porém, o presente texto focará na análise dos trabalhos sem cruzá-los com tais condições, ciente de que essa articulação também constitui um elemento potente a ser pesquisado. Na próxima seção, apresentaremos considerações a partir das categorias analíticas que elencamos. 
GÊNERO, SEXUALIDADE E FORMAÇÃO DE PROFESSORES EM DEBATE NA PESQUISA EDUCACIONAL

Levando em conta o objetivo já referido deste estudo, para refletir sobre as relações entre gênero, sexualidade e formação de professores a partir da produção acadêmica do GT 23 Gênero, Sexualidade e Educação da ANPEd, no período de 2004 a 2014, organizamos três unidades de sentido que nos permitiram discutir os significados que foram atribuídos às relações de gênero e às sexualidades pelas pesquisas que focalizavam a formação de professores, e em que medida estas estavam implicadas na constituição de significações a partir do uso que delas fazemos. Essas três unidades de sentido são apresentadas a seguir.

\section{(1) FEMINIZAÇÃO DO MAGISTÉRIO E CONSTITUIÇÃO DA DOCÊNCIA}

A primeira unidade de sentido foi organizada a partir dos trabalhos que examinaram a constituição da identidade docente articulada aos processos de feminização do magistério. Começamos nossa análise apresentando o estudo desenvolvido por Lúcia P. S. Villas Bôas, Clarilza P. de Sousa e Maria Rosa Lombardi (2012). ${ }^{8}$ As autoras mostram como diferentes aspectos históricos têm contribuído para a feminização da profissão docente no Brasil, apontando para a existência de uma representação da docência que parece consoante ao modelo de feminino e de feminilidade convencional que prevalece na sociedade brasileira.

No ano de 2010, o trabalho escrito por Sônia M. da S. Araújo, ao discutir os processos relativos à constituição da docência na Amazônia, mostra que a herança cultural das professoras pesquisadas, aliada às condições de sobrevivência econômica e às perspectivas de vida para além do mundo rural revelam histórias de resistência em que ser mulher tem se apresentado como condição para lutar e fazer a diferença nessas localidades.

No ano de 2007, encontramos mais dois trabalhos. Destacamos o trabalho de Marli L. T. Zibetti, que, ao investigar o que pensam as professoras de Educação Infantil sobre a feminização da profissão docente, mostra que o discurso de que as mulheres possuem capacidades inerentes ao trabalho com crianças pequenas está presente entre as próprias professoras participantes da pesquisa. A autora considera relevante destacar que esse não se constitui um discurso hegemônico, pois algumas das participantes do estudo apresentam questionamentos sobre a discriminação e os estereótipos que desvalorizam o trabalho em creches e pré-escolas. Ainda em 2007, temos o trabalho desenvolvido por Marisa Barletto, que, ao investigar sobre 
memórias e trajetórias na formação de pedagogas, destacou como um dos achados mais importantes entre as narrativas das pedagogas participantes do estudo, as pequenas revoluções nas vidas das pedagogas, atribuídas ao curso de Pedagogia. Segundo a pesquisadora, a dimensão curricular mais importante estava menos nos conteúdos e mais na possibilidade de as pedagogas conhecerem pessoas diferentes, referências culturais e conviverem com pessoas e situações adversas (BARLETTO, 2007).

O último trabalho vinculado a essa categoria foi apresentado no ano de 2004 e desenvolvido por Fábio Vasconcelos e Maria Celeste de M. Andrade. Intitulado"A mulher professora: gênero e constituição da identidade docente", nele os autores analisam o discurso bíblico a partir de autores pós-estruturalistas e mostram que podem ser identificados nesse discurso elementos do imaginário sobre a mulher educadora, sobre diferenças entre sexo e gênero no decorrer da história, e como os significados contidos nesse discurso produzem subjetividades para a constituição da mulher professora. Esse trabalho, além de trazer importantes contribuições para que possamos refletir sobre como a identidade docente se constitui em diferentes espaços para além dos espaços formalizados de formação docente, mostra que esse é um dos questionamentos que emerge junto com a criação do grupo de trabalho de Gênero, Sexualidade e Educação.

Ao olhar para a feminização do magistério como um processo histórico e cultural, e que também demarcou atravessamentos políticos, Guacira Louro (2011) nos faz refletir que o espaço da docência, ao mesmo tempo em que, politicamente, constituiu-se importante para as lutas feministas, por ser um dos primeiros espaços de trabalho a serem ocupados por mulheres fora do espaço doméstico, aos poucos, foi também se tornando enredado numa teia de sentidos produzidos pela linguagem, que conferiu à profissão docente, e ao trabalho da mulher nesse espaço, um estatuto de extensão do lar.

Não queremos, com isso, desmerecer as relações de proximidade que professoras mulheres tenham (ou não) com os espaços onde exerçam a docência, mas o que nos chama atenção é o modo como, junto com essa feminização do magistério, também foi sendo gestado um movimento aparente de simplificação e de precarização do trabalho da professora e do professor, fato que tem se tornado motivo para diversas mobilizações sindicais em defesa de melhores condições para essas e esses profissionais em todo o país. $\mathrm{O}$ que desejamos provocar com essa breve síntese é mostrar como as questões de gênero e sexualidade parecem silenciadas e/ou secundarizadas em tais debates. Assim, ao darmos visibilidade aos modos como gênero e sexualidade 
são abordados na formação de professores, a partir da produção acadêmica de um grupo de pesquisadores e pesquisadoras, desejamos marcar também uma posição política e ressaltar a importância de tais questões ganharem mais visibilidade diante desse cenário de precarização do trabalho docente. ${ }^{9}$

(2) NaturalizaÇÃo dAS DIFERENÇAS DE GÊNERO E DE SEXUALIDADE NA FORMAÇÃO DE PROFESSORES

Na segunda unidade de sentido, agrupamos os trabalhos que discorrem sobre a inserção de sujeitos que não têm tradicionalmente ocupado o espaço escolar e que, ao começarem a frequentar esses espaços, suscitam tensionamentos importantes, criando condições de possibilidade para a discussão das temáticas de gênero e sexualidade na formação de professores.

Queremos destacar, primeiramente, o trabalho de Mariana K. Monteiro e Helena Altmann (2013), que examinou as trajetórias docentes de professores homens na Educação Infantil; o trabalho de Rogério $M$. Rosa (2010), que investigou o modo como professores de Ensino Médio, que não estão integrados nos domínios da masculinidade hegemônica, experienciam seus corpos e constroem suas masculinidades na relação com atividade docente; e o trabalho de Frederico A. Cardoso (2007), que discute de que modos os professores homens não identificam o magistério como uma profissão exclusivamente feminina, mesmo com uma produção cultural de discursos sobre a relação do magistério com as mulheres. Ao mesmo tempo, o autor também identificou como uma marca da identidade masculina o trânsito na carreira docente, mostrando que os homens têm fugido de espaços como alfabetização, e procurado ocupar espaços na Educação Física ou na Gestão da Educação, espaços esses que, segundo o autor, ainda são notadamente demarcados para as vivências de suas masculinidades (CARDOSO, 2007).

Esses três trabalhos, produzidos respectivamente em 2013, 2010 e 2007, mostram uma preocupação das pesquisadoras e dos pesquisadores, que fazem parte do GT 23, com relação à inserção de professores homens no espaço escolar e como esses homens têm se relacionado e experienciado suas masculinidades em um contexto marcado pelo feminino, o que mostra um movimento, no GT, de tensionamento e de posicionamento em relação aos processos de naturalização das relações de gênero em espaços escolares e nos modos de exercer a docência.

Ainda nessa categoria, gostaríamos de destacar, do ano de 2013, os trabalhos de Marco A. Torres, que analisa a emergência da rede TRANS 
EDUC BRASIL, olhando para os significados construídos sobre docência, transexualidade e travestilidade, e o trabalho de Neil Franco e Graça A. Cicillini, que trouxe contribuições para a reflexão sobre o processo de escolarização de professoras travestis e transexuais.

No ano de 2012, destacamos o trabalho de Liane K. Rizzato, que, ao investigar as percepções dos docentes sobre homofobia na escola, mostrou que as compreensões dos professores são compostas a partir de suas experiências pessoais, e que os professores participantes dessa pesquisa relatavam múltiplas situações de violência vividas. Um ano antes, Lucélia de M. B. Bassalo (2011), ao investigar os significados atribuídos à homossexualidade pelos professores e professoras, mapeou três posicionamentos distintos: negação, revisão e defesa. Do mesmo ano, destacamos mais um trabalho, produzido por Neil Franco juntamente com Maria V. S. Mota (2011), que, ao buscar compreender e problematizar aspectos da constituição identitária de professores que transitam pelas fronteiras das sexualidades e de gênero, mostraram que permanece um sentimento de estranhamento e repulsa com esses sujeitos na escola. Para finalizar o mapeamento desse grupo, temos a pesquisa de Mirian P. Silva (2007), que, ao analisar as narrativas de três professores de Ciências sobre as temáticas de gênero e sexualidade, destacou que o currículo de formação de professores pode se constituir como um espaço onde experiências e subjetividades são constituídas e que elas não podem ser deslocadas da constituição do "ser professor".

O que queremos aqui ressaltar é o deslocamento dos professores que compuseram a investigação de Mirian Silva (2007), para os professores e professoras que integraram as pesquisas de Torres (2013) e de Franco e Cicillini (2013), nos anos seguintes. Silva (2007) destaca que esses professores sentiam a necessidade de esconder sua sexualidade tanto de alunos como de colegas, sentindo grande insatisfação por essa necessidade. Nos trabalhos apresentados em 2013, Marco Torres (2013), Neil Franco e Graça Cicillini (2013) assinalaram outros significados construídos para docência, na articulação com a transexualidade e a travestilidade. Entendemos que esse é um deslocamento bastante significativo, em pouco espaço de tempo, e acreditamos que o conhecimento produzido no interior do próprio GT possa ter contribuído para tal deslocamento.

Ainda com relação a esse deslocamento, fazemos duas considerações: primeira, essas análises só se tornaram potentes no momento em que foram realizadas nos referidos estudos, porque os processos de naturalização das diferenças de gênero e de sexualidade vinham constituindo os espaços da docência; segunda, essa materialização dessas diferenças nos estudos sobre 
formação de professores só foi estabelecida e pode ser identificada porque elas foram consideradas desviantes em relação às normas constituídas. Como nos ensina François Ewald (2000), a norma distingue e ao mesmo tempo torna comparável, e, por isso, funciona como medida comum que permite avaliar todos e todas - separando-os em normais e anormais, regulando e conformando aquilo que entendemos por bom professor e boa professora, por exemplo.

\section{(3) GÊNERO E SEXUALIDADE EM FOCO NA FORMAÇÃO DE PROFESSORES}

Nesta terceira e última unidade de sentido, destacamos pesquisas que focalizaram os temas gênero e sexualidade para investigar a formação de professores. Através de diferentes estratégias, as pesquisadoras e pesquisadores assinalam a importância da inserção dos conceitos de gênero e de sexualidade em suas pesquisas, e apresentam diferentes estratégias para esse trabalho.

Começamos pelas pesquisas apresentadas no ano de 2014. Nesse ano, Roney P. de Castro apresentou uma pesquisa que teve como objetivo problematizar as relações entre formação docente no curso de Pedagogia, gênero e sexualidade. $O$ autor verificou que muitas das alunas participantes do estudo expressaram em suas narrativas conflitos produzidos entre a formação religiosa recebida na educação familiar e as desconstruções propostas pela disciplina (CASTRO, 2014).

A pesquisa de Éderson da Cruz e Maria Cláudia Dal'Igna (2014) também focalizou o ensino superior para problematizar a relação entre gênero e currículo no âmbito da formação inicial de docentes. Os autores mostraram que, na formação de professores, um dos processos de naturalização das relações de gênero ocorre por meio da visão dicotômica do currículo, que polariza teoria ("currículo do papel") e prática ("currículo em movimento"), o que permite identificar tensionamentos de gênero somente na dimensão prática dessa formação (CRUZ; DAL'IGNA, 2014).

Para finalizar os trabalhos apresentados em 2014, temos a pesquisa desenvolvida por Marcos L. de Souza. Nela, o autor investiga o Pibid (Programa Institucional de Bolsa de Iniciação à Docência) como espaço formativo, narrando e discutindo os desafios enfrentados pelos participantes do Programa, relacionados às questões de gênero e de sexualidade. Entre os principais resultados do trabalho, pode-se destacar a tensão entre família e escola, marcada muitas vezes por discursos religiosos, que ao mesmo tempo se constituem como uma situação imobilizadora das ações da escola, em outros momentos também potencializam essas ações (SOUZA, 2014). 
No ano de 2013, queremos destacar os estudos de Roney P. de Castro, que, ao analisar diários de bordo produzidos por estudantes de Pedagogia em uma disciplina que busca tensionar os conceitos de gênero e de sexualidade a partir de uma perspectiva pós-estruturalista, mostra que esses diários podem estar funcionando como mecanismos de subjetivação e registram deslocamentos das estudantes sobre suas ideias/comportamentos e seus valores vinculados às relações de gênero e sexualidade; e de Taisa de $S$. Ferreira (2013), que, ao investigar a presença de gênero e de sexualidade no curso de Pedagogia, mostra que os docentes desse curso assinalam a presença de gênero e sexualidade no curso como "audácias e estripulias" em arranjos que ora tensionam, ora silenciam essas questões.

Do ano de 2012, destaca-se o trabalho de Cláudia M. Ribeiro, que, ao problematizar as falas de educadoras que atuam na Educação Infantil, aponta e discute alguns temas que emergiram na fala das professoras, como os conflitos existentes na educação para sexualidade, os genitais das crianças, a erotização precoce e os textos culturais, tais como novelas, música e religião. Em 2011, temos o estudo de Roney P. de Castro e Anderson Ferrari, que ao buscarem um diálogo entre formação docente e as questões de gênero e sexualidade, realizaram observações participantes em uma disciplina que enfocou essa temática com alunas de Pedagogia, e assim investigaram quais as implicações políticas e culturais de incluir questões relativas ao gênero e à sexualidade nos currículos de formação inicial de professores.

Em 2008, outro trabalho escrito por Roney P. de Castro, que ao se propor discutir a constituição de sujeitos no contexto de um programa que se destinou a refletir sobre educação afetivo-social com professores, mostrou que as escolas parecem optar por conduzir atividades ligadas à sexualidade de forma bastante cautelosa, buscando refúgio no campo científico; entretanto, foi possível visualizar entre os participantes do processo de formação alguns deslocamentos dessas práticas, contextualizando social e culturalmente algumas dessas questões.

No mesmo ano, o trabalho desenvolvido por Cintia de S. B. Tortato (2008) investigou um trabalho formativo, objetivando discutir algumas questões voltadas para gênero e sexualidade a partir da literatura infantil, tendo como público-alvo profissionais que atuam na Educação Infantil e no Ensino Fundamental, com destaque para a importância de se trabalhar as questões de gênero e diversidade sexual na escola. Segundo a pesquisadora, foi visível a satisfação dos participantes nas atividades que envolveram os livros infantis, pois esses participantes puderam ver nos livros uma ferramenta 
que poderia ser utilizada como suporte para discussão dessas temáticas no cotidiano escolar (TORTATO, 2008).

Para finalizar essa categoria, destacamos o trabalho da pesquisadora Maria Cláudia Dal'Igna (2005), que, ao realizar um estudo com professoras de séries iniciais sobre desempenho escolar e gênero, mostra que as práticas pedagógicas desenvolvidas pelas professoras estão implicadas na produção de determinados "jeitos de ser" menino e menina, o que produz hierarquias e desigualdades relativas ao desempenho escolar. Para a autora esses processos de diferenciação distinguem meninos de meninas, mas também meninos de meninos e meninas de meninas, e ao mesmo tempo torna cada feminilidade e masculinidade comparável (DAL'IGNA, 2005).

Ao concluir a apresentação dos trabalhos selecionados nessa unidade de sentido, ressaltamos a visibilidade da discussão dessas temáticas, tanto na formação inicial como continuada de docentes. Mas consideramos pertinente lembrar, como os trabalhos apresentados também destacaram, que mesmo que possa ser visível a ampliação de conhecimentos, a reflexão e os debates em torno das temáticas de gênero e sexualidade, não devemos entender esses movimentos como garantia de mudanças definitivas dos comportamentos discriminatórios que ocorrem na escola e na universidade com os diferentes sujeitos envolvidos.

Essa unidade de sentido também, direta ou indiretamente, ao focar questões de gênero e de sexualidade, olhando para espaços educativos, acaba por focalizar o currículo. Cabe-nos aqui lembrar das contribuições da autora Marlucy Paraíso (2010), cujo trabalho tem mostrado que os currículos de formação de professores são artefatos generificados, tanto quando refletem a preocupação com a realização de discussões sobre gênero e sexualidade, quando não refletem, pois, de alguma forma, as construções de gênero e de sexualidade acabam por atravessar e dimensionar esses artefatos, tanto no sentido de uma tendência à normatização e ao silenciamento das diferenças, quanto no sentido de uma subversão dessa lógica. E mesmo que esse currículo não se proponha a abordar esses temas, o silenciamento também ensina sobre gênero e sexualidade.

\section{ConsideraçõES FINAIS}

Nosso objetivo neste artigo foi apresentar e discutir os resultados de uma análise realizada a partir da produção acadêmica da Associação Nacional de Pesquisadores em Educação (ANPEd), que se constitui como uma importante associação de pesquisa em educação do Brasil, especialmente aquela desenvolvida por pesquisadoras e pesquisadores vinculados ao Grupo 
de Trabalho 23 (GT 23): Gênero, Sexualidade e Educação. Essas pesquisas analisadas têm produzido dados importantes para pensarmos a formação de professores no contexto atual do nosso país, desde a perspectiva das relações de gênero e das sexualidades.

Além de encontrar uma diversificada produção acadêmica sobre as temáticas examinadas, no decorrer de nossa análise, fomos percebendo, além dos pontos já destacados, outros aspectos que nos levaram aos questionamentos a seguir.

Em primeiro lugar, nota-se que existe um deslocamento no quadro dos trabalhos publicados sobre formação de professores no GT 23 Gênero, Sexualidade e Educação. Percebemos que, inicialmente, os trabalhos que discutiam formação de professores no GT tinham como foco a investigação da feminização do magistério e a constituição da identidade docente. Após, a ênfase desloca-se para pensar como as diferenças de gênero e de sexualidade, ao entrar nos espaços da educação básica e superior, começam a fomentar mudanças significativas na produção acadêmica sobre a formação de professores. Juntamente, vemos surgir os trabalhos que discorrem sobre a importância de inserirmos a discussão relativa ao gênero e à sexualidade nos cursos de formação inicial e continuada de docentes, tensionando, inclusive, os processos de naturalização de gênero e sexualidade em ação nos currículos escolares e universitários, no âmbito no qual a profissão docente vem sendo constituída.

Em segundo lugar, é importante fazer um destaque com relação à quantidade de trabalhos, os quais têm se mantido constantes, pois praticamente em todos os anos temos uma média de dois a quatro trabalhos que buscam focalizar as relações de gênero e as sexualidades em articulação com a formação de professores no GT analisado - ainda que exista um GT específico para discutir a formação de professores no mesmo evento (GT 08). O questionamento que poderia emergir é que a discussão de formação de professores tem sido encontrada presente no GT Gênero, Sexualidade e Educação, mas essa discussão parece silenciada nos outros GTs analisados. Assim, entendemos que estudos como os de Márcia Ondina Ferreira (2010, 2015, 2017), já referidos, que analisam os trabalhos apresentados nos anos anteriores à criação do GT Gênero, Sexualidade e Educação, são importantes para discutirmos a inexistência, visibilidade e legitimidade das discussões na ANPEd sobre gênero e sexualidade na formação de professores.

Sobre esse último ponto, ressaltamos que a presença, na ANPEd, de um GT que discute gênero, sexualidade e educação não pode ser justificada apenas por meio de discussões que articulam esses elementos à formação 
docente, haja vista já existir, na ANPEd, um GT que discute essa formação. No entanto, uma vez que essa formação não tem sido discutida no GT Formação de Professores a partir de perspectivas que articulam gênero e sexualidade, são criadas condições de possibilidade para que o GT Gênero, Sexualidade e Educação assuma tal função, ao mesmo tempo em que, ao serem deslocadas do GT Formação de Professores para o GT Gênero, Sexualidade e Educação, pode-se refletir sobre uma certa secundarização das dimensões de gênero e de sexualidade pelo campo da formação docente.

Tais apontamentos reforçam a importância de que a questão da formação docente não seja excluída das discussões e trabalhos apresentados no GT 23 Gênero, Sexualidade e Educação, porém também mostram a necessidade de movimentos, dentro do próprio GT, de desnaturalização de uma cultura acadêmica de que somente nesse espaço tais questões devam ser discutidas, ainda que articuladas a temas caros a outros GTs. Isso evidencia a importância da ampliação do escopo dessas pesquisas no GT 23 Gênero, Sexualidade e Educação, a fim de impulsionar e de articular essas discussões a outros espaços e a outros GTs da ANPEd, de modo a promover tensionamentos e outras formas de estudar a própria formação de professores. Por fim, espera-se que, com a análise apresentada aqui sobre os modos como gênero e sexualidade são abordados ao focalizar a formação de professores no GT Gênero e Sexualidade e Educação, se possa impulsionar outras pesquisas para além daquelas que constituem o corpus analítico desse trabalho e daquelas que estão sendo desenvolvidas, no tempo presente, a partir do exame desse material empírico. Esperamos, ainda, que a argumentação aqui desenvolvida possa possibilitar manter vivas as nossas perguntas e afi(n)ar nossos olhares diante das diferenças e das desigualdades de gênero e de sexualidade que se constituem no exercício da docência e que produzem a própria docência. Afinal, ainda há muito o que fazer/dizer/investigar sobre gênero, sexualidade e formação de docentes em nosso país! 
GENDER, SEXUALITY ANDTEACHERTRAINING: AN ANALYSIS FROMTHE ACADEMIC PRODUCTION OF THE ANPED

ABSTRACT: This article presents and discusses the results of an analysis carried out from the academic production of an important association of research in education in Brazil, ANPEd, especially that developed by researchers linked to GT 23: Gender, Sexuality and Education. This analysis was elaborated to subsidize a set of researches carried out in the South region of Brazil, linked to a Post-Graduate Program in Education. From this production, taking as a theoretical reference the Gender Studies and the Foucaultian Studies, the present article seeks to examine 25 papers presented at annual meetings between 2004 and 2014. This analysis makes it possible to reflect on the ways in which gender and sexuality are approached by focusing on teacher education, and offers contributions so that future research problems can be built and delimited on these topics.

KEYWORDS: Gender. Sexuality. Teacher training. ANPEd.

GÉNERO, SEXUALIDADY FORMACIÓN DE PROFESORES: UN ANÁLISIS A PARTIR DE LA PRODUCCIÓN ACADÉMICA DE LA ANPED

RESUMEN: Este artículo presenta y discute los resultados de un análisis realizado a partir de la producción académica de una importante asociación de investigación en educación de Brasil, la ANPEd, especialmente aquella desarrollada por investigadores e investigadoras vinculados al GT 23: Género, Sexualidad y Educación. Dicho análisis fue elaborado para subsidiar un conjunto de investigaciones realizadas en la región sur de Brasil, vinculadas a un programa de pos graduación en Educación. A partir de esa producción, tomando como referencial teórico los Estudios de Género y los Estudios Foucaultianos, el presente artículo busca examinar 25 trabajos presentados en reuniones anuales en el período entre 2004 y 2014 . Este análisis nos da la posibilidad de reflexionar de qué manera género y sexualidad son abordados al focalizar la formación de profesores, y ofrece contribuciones para que se pueda construir y delimitar futuros problemas de investigaciones sobre estos temas.

Palabras Clave: Género. Sexualidad. Formación de profesores. ANPEd.

\section{NotAs}

1 Agradecemos ao Conselho Nacional de Desenvolvimento Científico e Tecnológico $(\mathrm{CNPq})$ e à Coordenação de Aperfeiçoamento de Pessoal de Nível Superior (Capes) pelo apoio financeiro concedido aos estudos que deram origem a este artigo e a equipe de pesquisa coordenada pela professora Maria Cláudia Dal'Igna. 
2 Para conferir maior fluidez ao texto, adotamos o uso dos substantivos a partir das regras de uso que regem a norma padrão da Língua Portuguesa - ou seja - apenas na flexão masculina. Isso não significa, no entanto, que tal norma não deva ser tensionada, justamente por posicionar os sujeitos no mundo e articulá-los em relações de poder, como tentamos mostrar ao destacarmos o nosso posicionamento teórico decorrente de uma aproximação com o campo dos Estudos de Gênero. Para esse momento, mesmo cientes de tais questões, optamos por dar visibilidade às flexões de gênero (tais como "professores e professoras" ou "alunos e alunas") somente quando for considerado relevante para o escopo da discussão. Do mesmo modo, adotamos o uso da expressão "formação de professores", ao invés de "formação de docentes", por reconhecer que este é um campo de produção de conhecimentos consolidado em nosso país.

3 Pesquisa mais abrangente, desenvolvida no Programa de Pós-Graduação em Educação da Unisinos: "Pibid/Capes: impactos de uma política de formação inicial na construção da identidade profissional da pedagoga" (DAL'IGNA, 2017). Pesquisas de doutorado e de graduação/iniciação científica, citadas respectivamente, integrantes do projeto de pesquisa mais abrangente: "Metamorfoses no mundo do trabalho docente: uma analítica de gênero" (SCHERER, 2017); "Homens, cinema e docência: masculinidades na "telona" (CRUZ, 2017); "Gênero, Sexualidade e Profissionalidade: uma análise das narrativas de docentes homossexuais" (SILVA, 2018); “Famílias homo parentais: implicações para a formação do pedagogo" (PRADO, 2017).

4 Mauro Condé (1998), comentando as implicações do pensamento de Wittgenstein para a noção de linguagem, afirma que a pergunta sobre os diferentes usos que fazemos da linguagem indica uma recusa da busca de sua essência ou, ainda, a negação da possibilidade de uma linguagem universal.

5 Dagmar Meyer, Maria Cláudia Dal'Igna e Maria Simone Schwengber (2015, p. 185), ao analisar o verbete Educação, explicam que:"o ato ou processo de educar ou educar-se no mundo inclui o conhecimento e desenvolvimento resultantes desse ato ou processo. Nesse sentido, o termo educar reúne dois grupos de significados, associados aos termos educare - de fora para dentro do indivíduo, com o sentido de orientar, levá-lo do ponto em que se encontra para outro que se deseja alcançar - e educere - de dentro para fora, no sentido de promover as potencialidades que o indivíduo possui" (grifo das autoras).

6 Desde 2000, a ANPEd disponibiliza uma versão completa de cada trabalho e pôster apresentados nos grupos de trabalho, nas reuniões científicas nacionais. Para maiores detalhes, ver: <http://www.anped.org.br/>.

7 Uma versão preliminar e simplificada deste texto foi apresentada em uma reunião regional da ANPEd. Para maiores detalhes, ver Renata Scherer e Éderson da Cruz (2016).

8 Os trabalhos referidos nesta seção foram apresentados em reuniões anuais da ANPEd, e estão disponíveis no site da associação, <http://www.anped.org.br/reunioes- 
-cientificas/nacional>, no banco de dados do GT Gênero e Sexualidade e Educação, conforme o ano de realização. Considerando que tais trabalhos são usados neste artigo como materiais empíricos, e não como fontes bibliográficas, optamos por não citar os trabalhos nas referências.

9 A precarização do trabalho docente sob uma perspectiva de gênero é um dos focos analisados por duas de nós em outras pesquisas que desenvolvemos. Para ampliar as reflexões sobre essa questão, ver Renata Scherer e Maria Cláudia Dal'Igna (2017).

\section{REFERÊNCIAS}

ALVES-MAZZOTI, A. J. Revisão da Bibliografia. In: ALVES MAZZOTI, A. J.; GEWANDSZNAJDER, F. O método nas Ciências Naturais e Sociais: pesquisa quantitativa e qualitativa. São Paulo: Pioneira, 1998, p. 179-188.

ARAÚJO, S. M. da S. Constituir-se professora na Amazônia: história de mulheres mestiças da região de ilhas de Belém. In: REUNIÃO ANUAL DA ASSOCIAÇÃO NACIONAL DE PÓS-GRADUAÇÃO E PESQUISA EM EDUCAÇÃO - ANPEd, 33, 2010, Caxambu/MG. Anais... Educação no Brasil: O balanço de uma Década. Rio de Janeiro: ANPEd, 2010

BARLETTO, M. Formação de pedagogas - memórias e trajetórias. In: REUNIÃO ANUAL DA ASSOCIAÇÃO NACIONAL DE PÓS-GRADUAÇÃO E PESQUISA EM EDUCAÇÃO ANPEd, 30, 2007, Caxambu/MG. Anais... Constituição Brasileira, Direitos Humanos e Educação. Rio de Janeiro: ANPEd, 2007.

BASSALO, L. de M. Heteronormatividade ou reconhecimento? professores e professoras diante da homossexualidade. In: REUNIÃO ANUAL DA ASSOCIAÇÃO NACIONAL DE PÓS-GRADUAÇÃO E PESQUISA EM EDUCAÇÃO - ANPEd, 34, 2010, Natal/RN. Anais... Educação e justiça social. Rio de Janeiro: ANPEd, 2011.

BÔAS, L. P. S. V.; SOUSA, C. P. de; LOMBARDI, M. R.. Trabalho docente na ótica de estudantes brasileiros(as): das representações sociais às relações sociais de sexo. In: REUNIÃO ANUAL DA ASSOCIAÇÃO NACIONAL DE PÓS-GRADUAÇÃO E PESQUISA EM EDUCAÇÃO - ANPEd, 35, 2012, Porto de Galinhas/PE, Anais... Educação, Cultura, Pesquisa e Projetos de Desenvolvimento: o Brasil do século XXI. Rio de Janeiro: ANPEd, 2012 CARDOSO, F. A. Homens fora de lugar? A identidade de professores homens na docência com crianças. In: REUNIÃO ANUAL DA ASSOCIAÇÃO NACIONAL DE PÓS-GRADUAÇÃO E PESQUISA EM EDUCAÇÃO - ANPEd, 30, 2007, Caxambu/MG. Anais... Constituição Brasileira, Direitos Humanos e Educação. Rio de Janeiro: ANPEd, 2007.

CASTRO, R.P. de. Escritas-narrativas de estudantes problematizando relações de gênero e sexualidades. In: REUNIÃO ANUAL DA ASSOCIAÇÃO NACIONAL DE PÓS-GRADUAÇÃO E PESQUISA EM EDUCAÇÃO - ANPEd, 36, 2013, Goiânia/GO. Anais... Sistema Nacional de Educação e Participação Popular: Desafios para as Políticas Educacionais. Rio de Janeiro: ANPEd, 2013 
CASTRO, R. P. de; FERRARI, A. "Nossa! Eu nunca tinha parado pra pensar nisso!" - gênero, sexualidades e formação docente. In: REUNIÃO ANUAL DA ASSOCIAÇÃO NACIONAL DE PÓS-GRADUAÇÃO E PESQUISA EM EDUCAÇÃO - ANPEd, 34, 2010, Natal/RN. Anais... Educação e justiça social. Rio de Janeiro: ANPEd, 2011.

CASTRO, R. P. de. Professores(as), sexualidade e educação sexual: produzindo sujeitos nos contextos do programa de educação afetivo-sexual (peas). In: REUNIÃO ANUAL DA ASSOCIAÇÃO NACIONAL DE PÓS-GRADUAÇÃO E PESQUISA EM EDUCAÇÃO - ANPEd, 31, 2008, CAXAMBU/MG. ANPEd Constituição Brasileira, Direitos Humanos e Educação. Rio de Janeiro: ANPEd, 2008.

CASTRO, R. P. de. Formação docente, experiência religiosa e sexualidades: problematizações. In: REUNIÃO ANUAL DA ASSOCIAÇÃO NACIONAL DE PÓS-GRADUAÇÃO E PESQUISA EM EDUCAÇÃO - ANPEd, 37, 2014, Florianópolis/SC. Anais... Plano Nacional de Educação: tensões e perspectivas para a educação pública brasileira. Rio de Janeiro: ANPEd, 2014.

CONDÉ, M. L. L. Wittgenstein: linguagem e mundo. São Paulo: Annablume, 1998.

CRUZ, É. da. Homens, cinema e docência: masculinidades na "telona". Projeto de Tese (Doutorado em Educação) - Universidade do Vale do Rio dos Sinos, São Leopoldo/ RS, 2017.

CRUZ, É. da; DAL'IGNA, M. C. Gênero e currículo: uma análise dessa (des)articulação na formação inicial de docentes. In: REUNIÃO ANUAL DA ASSOCIAÇÃO NACIONAL DE PÓS-GRADUAÇÃO E PESQUISA EM EDUCAÇÃO - ANPEd, 37, 2014, Florianópolis/SC. Anais... Plano Nacional de Educação: tensões e perspectivas para a educação pública brasileira. Rio de Janeiro: ANPEd, 2014.

DAL'IGNA, M. C. Desempenho escolar e gênero: um estudo com professoras de séries iniciais. In: REUNIÃO ANUAL DA ASSOCIAÇÃO NACIONAL DE PÓS-GRADUAÇÃO E PESQUISA EM EDUCAÇÃO - ANPEd, 28. 2005, Caxambu/MG. Anais... 40 anos da Pós-Graduação em Educação no Brasil. Rio de Janeiro: ANPEd, 2005.

DAL'IGNA, M. C. Relatório final de atividades de projeto de pesquisa. Pibid/Capes: impactos de uma política de formação inicial na construção da identidade profissional da pedagoga (2013-2017). São Leopoldo: Programa de Pós-Graduação em Educação, Universidade do Vale do Rio dos Sinos. 2017. [Relatório de Pesquisa].

EWALD, F. Foucault, a norma e o Direito. 2. ed. Tradução de António F. Cascais. Lisboa: Veja, 2000.

FERREIRA, M. O. V. O campo do gênero na ANPEd: hipóteses em construção. In: REUNIÃO ANUAL DA ASSOCIAÇÃO NACIONAL DE PÓS-GRADUAÇÃO E PESQUISA EM EDUCAÇÃO - ANPEd, 37, 2015. Florianópolis/ SC. Anais... PNE: tensões e perspectivas para a educação brasileira. Rio de Janeiro: ANPEd, 2015.

FERREIRA, M. O. V.; CORONEL, M. Sobre a legitimação do campo do gênero na ANPEd. Educação e Pesquisa, v. 43, n. 3, p. 815-831, jul./set., 2017. 
FERREIRA, M. O. V.; NUNES, G. H. L. Panorama da produção sobre gênero e sexualidades apresentada nas reuniões da ANPEd (2000-2006). In: REUNIÃO ANUAL DA ASSOCIAÇÃO NACIONAL DE PÓS-GRADUAÇÃO E PESQUISA EM EDUCAÇÃO - ANPEd, 29, 2006, Caxambu/MG. Anais... Educação no Brasil: O balanço de uma Década. Rio de Janeiro: ANPEd, 2010.

FERREIRA, T. de S. Modos de ver, sentir, e questionar: a presença do gênero e da sexualidade no curso de Pedagogia. In: REUNIÃO ANUAL DA ASSOCIAÇÃO NACIONAL DE PÓS-GRADUAÇÃO E PESQUISA EM EDUCAÇÃO - ANPEd, 36, 2013, Goiânia/GO. Anais... Sistema Nacional de Educação e Participação Popular: Desafios para as Políticas Educacionais. Rio de Janeiro: ANPEd, 2013.

FRANCO, N.; CICILLINI, G. A. Professoras travestis e transexuais brasileiras e seu processo de escolarização: caminhos percorridos e obstáculos enfrentados. In: REUNIÃO ANUAL DA ASSOCIAÇÃO NACIONAL DE PÓS-GRADUAÇÃO E PESQUISA EM EDUCAÇÃO - ANPEd, 36, 2013, Goiânia/GO. Anais... Sistema Nacional de Educação e Participação Popular: Desafios para as Políticas Educacionais. Rio de Janeiro: ANPEd, 2013.

FRANCO, N.; MOTA, M. V. S. Visibilidade da sexualidade do/a docente homossexual na escola. In: REUNIÃO ANUAL DA ASSOCIAÇÃO NACIONAL DE PÓS-GRADUAÇÃO E PESQUISA EM EDUCAÇÃO - ANPEd, 34, 2010, Natal/RN. Anais... Educação e justiça social. Rio de Janeiro: ANPEd, 2011.

LOURO, G. L. Gênero, Sexualidade e Educação - das afinidades políticas às tensões teórico-metodológicas. In: REUNIÃO ANUAL DA ASSOCIAÇÃO NACIONAL DE PÓS-GRADUAÇÃO E PESQUISA EM EDUCAÇÃO - ANPEd, 29, 2006, Caxambu/MG. Anais... Educação, Cultura e conhecimento na Contemporaneidade: desafios e compromissos. Rio de Janeiro: ANPEd, 2006.

LOURO, G. L. Gênero, sexualidade e educação: uma perspectiva pós-estruturalista. 16. ed. Rio de Janeiro: Vozes, 2011.

MEYER, D. E. E.; RIBEIRO, C.; RIBEIRO, P. R. M. Gênero, sexualidade e educação: "olhares" sobre algumas das perspectivas teórico-metodológicas que instituem um novo G.E. In: REUNIÃO ANUAL DA ASSOCIAÇÃO NACIONAL DE PÓS-GRADUAÇÃO E PESQUISA EM EDUCAÇÃO - ANPEd, 27, 2004, Caxambu/MG. Anais... Rio de Janeiro: ANPEd, 2004. MEYER, Dagmar E. E. Abordagens pós-estruturalistas de pesquisa na interface educação, saúde e gênero: perspectiva metodológica. In: MEYER, D. E. E.; PARÍSO, M. A. (Org.). Metodologias Pós-críticas em Educação. 2. ed. Belo Horizonte: Massa, 2012, p. 47-61.

MEYER, D. E. E.; DAL'IGNA, M. C.; SCHWENGBER, M. S. Educação (verbete). In: COLLING, A. M.; TEDESCHINI, L. A.. Dicionário crítico de gênero. Dourados: UFGD, 2015, p. 185-188. MONTEIRO, M. K.; ALTMANN, H. Trajetórias na docência: professores homens na educação infantil. In: REUNIÃO ANUAL DA ASSOCIAÇÃO NACIONAL DE PÓS-GRADUAÇÃO E PESQUISA EM EDUCAÇÃO - ANPEd, 36, 2013, Goiânia/GO. Anais... Sistema Nacional 
de Educação e Participação Popular: Desafios para as Políticas Educacionais. Rio de Janeiro: ANPEd, 2013.

NICHOLSON, L. Interpretando o gênero. Revista Estudos Femininas, v. 8, n. 2, 2000.

PARAÍSO, M. A. Raciocínios generificados no currículo e possibilidades de aprender. In: COLÓQUIO LUSO-BRASILEIRO SOBRE QUESTÕES CURRICULARES. COLÓQUIO SOBRE QUESTÕES CURRICULARES, Porto, 2010. Anais... Porto: [s/n], 2010, p. 1-27.

PRADO, J. L. do. Famílias homoparentais: implicações para a formação do pedagogo. Projeto de Trabalho de Conclusão (Curso de Pedagogia) - Universidade do Vale do Rio dos Sinos, São Leopoldo/RS, 2017.

RIBEIRO, C. M. No labirinto da educação infantil as falas de educadoras sobre gênero e sexualidade. In: REUNIÃO ANUAL DA ASSOCIAÇÃO NACIONAL DE PÓS-GRADUAÇÃO E PESQUISA EM EDUCAÇÃO - ANPEd, 35, 2012, Porto de Galinhas/PE. Anais... Educação, Cultura, Pesquisa e Projetos de Desenvolvimento: o Brasil do século XXI. Rio de Janeiro: ANPEd, 2012.

RIBEIRO, C. M.; XAVIER FILHA, C. Trajetórias teórico-metodológicas em 10 anos de produção do GT 23". In: REUNIÃO ANUAL DA ASSOCIAÇÃO NACIONAL DE PÓS-GRADUAÇÃO E PESQUISA EM EDUCAÇÃO - ANPEd, 36, 2013, Goiânia/GO. Anais... Sistema Nacional de Educação e Participação Popular: Desafios para as Políticas Educacionais. Rio de Janeiro: ANPEd, 2013.

RIZZATO, L. K. Percepções docentes sobre a homofobia na escola: entre dissonâncias e continuidades. In: REUNIÃO ANUAL DA ASSOCIAÇÃO NACIONAL DE PÓS-GRADUAÇÃO E PESQUISA EM EDUCAÇÃO - ANPEd, 35, 2012, Porto de Galinhas/PE. Anais... Educação, Cultura, Pesquisa e Projetos de Desenvolvimento: o Brasil do século XXI. Rio de Janeiro: ANPEd, 2012.

ROSA, R. M. Corporeidades masculinas nômades: o espaço da docência como heterotopia. In: REUNIÃO ANUAL DA ASSOCIAÇÃO NACIONAL DE PÓS-GRADUAÇÃO E PESQUISA EM EDUCAÇÃO - ANPEd, 33, 2010, Caxambu/MG. Anais... Educação no Brasil: O balanço de uma Década. Rio de Janeiro: ANPEd, 2010.

SCOTT, J. Gênero: uma categoria útil de análise histórica. Educação e Realidade, Porto Alegre, v. 20, n. 2, jul./dez., 1995.

SCHERER, R. P. Metamorfoses no mundo do trabalho docente: uma analítica de gênero. Projeto de Tese (Doutorado em Educação) - Universidade do Vale do Rio dos Sinos, São Leopoldo/RS, 2017.

SCHERER, R. P.; CRUZ, É. da. Gênero, sexualidade e formação de professores: uma análise da produção científica da ANPEd entre 2004 e 2014. In: REUNIÃO CIENTÍFICA REGIONAL DA ASSOCIAÇÃO NACIONAL DE PÓS-GRADUAÇÃO E PESQUISA EM EDUCAÇÃO - ANPEd, 11, 2016, Curitiba/PR. Anais... Curitiba: Setor de Educação da UFPR, 2016. SCHERER, R. P.; DAL'IGNA, M. C. Amor, cuidado e competência: um olhar de gênero sobre a profissionalização do trabalho docente. In: REUNIÃO ANUAL DA ASSOCIAÇÃO 
NACIONAL DE PÓS-GRADUAÇÃO E PESQUISA EM EDUCAÇÃO - ANPEd, 38, 2017, São Luís do Maranhão/MA. Anais... Rio de Janeiro: ANPEd, 2017.

SILVA, J. V. da. Gênero, sexualidade e profissionalidade: uma análise das narrativas de docentes homossexuais. Trabalho de Conclusão (Curso de Pedagogia) - Universidade do Vale do Rio dos Sinos, São Leopoldo/RS, 2018.

SILVA, M. P. Quando o estranho é o professor: narrativas sobre sexualidade e o currículo de formação de professores. In: REUNIÃO ANUAL DA ASSOCIAÇÃO NACIONAL DE PÓS-GRADUAÇÃO E PESQUISA EM EDUCAÇÃO - ANPEd, 30, 2007, Caxambu/MG. Anais... Constituição Brasileira, Direitos Humanos e Educação. Rio de Janeiro: ANPEd, 2007.

SOUZA, M. L. de. O PIBID como espaço formativo de desarranjos, reinvenções e pluralizações dos gêneros e das sexualidades. In: REUNIÃO ANUAL DA ASSOCIAÇÃO NACIONAL DE PÓS-GRADUAÇÃO E PESQUISA EM EDUCAÇÃO - ANPEd, 37, 2014, Florianópolis/SC. Anais... Plano Nacional de Educação: tensões e perspectivas para a educação pública brasileira. Rio de Janeiro: ANPEd, 2014.

TORRES, M. A. Docência, transexualidades e travesilidades: a emergência rede TRANS EDUC Brasil. In: REUNIÃO ANUAL DA ASSOCIAÇÃO NACIONAL DE PÓS-GRADUAÇÃO E PESQUISA EM EDUCAÇÃO - ANPEd, 36, 2013, Goiânia/GO. Anais... Sistema Nacional de Educação e Participação Popular: Desafios para as Políticas Educacionais. Rio de Janeiro: ANPEd, 2013.

TORTATO, C. de S. B. Profissionais da educação infantil e ensino fundamental diante das questões de gênero e diversidade sexual: as possibilidades da literatura infantil. In: REUNIÃO ANUAL DA ASSOCIAÇÃO NACIONAL DE PÓS-GRADUAÇÃO E PESQUISA EM EDUCAÇÃO - ANPEd, 31, 2008, CAXAMBU/MG. Anais... constituição Brasileira, Direitos Humanos e Educação. Rio de Janeiro: ANPEd, 2008.

VASCONCELOS, F.; ANDRADE, M. C. de. A mulher professora: gênero e constituição da identidade docente. In: REUNIÃO ANUAL DA ASSOCIAÇÃO NACIONAL DE PÓS-GRADUAÇÃO E PESQUISA EM EDUCAÇÃO - ANPEd, 27, 2004, CAXAMBU/MG. Anais... Sociedade, Democracia, Educação. Rio de Janeiro: ANPEd, 2008.

ZIBETTI, M. L. T. O que pensam professoras de educação infantil sobre a feminização da profissão docente? In: REUNIÃO ANUAL DA ASSOCIAÇÃO NACIONAL DE PÓS-GRADUAÇÃO E PESQUISA EM EDUCAÇÃO - ANPEd, 30, 2007, Caxambu/MG. Anais... Constituição Brasileira, Direitos Humanos e Educação. Rio de Janeiro: ANPEd, 2007

Maria Cláudia Dal'Igna: Doutora em Educação. Professora do Curso de Pedagogia e do Programa de Pós-Graduação em Educação da Universidade do Vale do Rio dos Sinos (UNISINOS). É vice-líder do Grupo Interinstitucional de Pesquisa em Docências, Pedagogias e Diferenças (GIPEDI/Unisinos) (2015), e docente pesquisadora do Grupo de Estudos de Educação e Relações de Gênero (GEERGE/ UFRGS/CNPq) (2003). Suas pesquisas articulam os estudos de 
gênero pós-estruturalistas e os estudos foucaultianos para analisar os seguintes temas: pedagogia; formação de professores; profissionalidade docente; docência: afeto, amor e cuidado.

E-mail: mcdaligna@hotmail.com

Renata Porcher Scherer: Doutoranda e mestra em Educação, especialista em Educação Especial e licenciada em Educação Física pela Universidade do Vale do Rio dos Sinos (Unisinos). Integrante do Grupo Interinstitucional de Pesquisa em Docências, Pedagogias e Diferenças (GIPEDI). Tem experiência na Educação Básica, sendo professora na rede municipal de Portão, RS/Brasil, desde o ano de 2006. Desenvolve investigações sobre as temáticas de trabalho docente, educação inclusiva e gênero na Educação Básica.

E-mail: renata_ps3@yahoo.com.br

ÉdERSON DA CRUZ: Doutorando e Mestre em Educação, licenciado em Letras pela Universidade do Vale do Rio dos Sinos (Unisinos). Integrante do Grupo Interinstitucional de Pesquisa em Docências, Pedagogias e Diferenças (GIPEDI). É professor de literatura da Escola de Ensino Médio Nossa Senhora de Fátima, e regente de classe do Governo do Estado do Rio Grande do Sul. Tem experiência na área de Letras, com ênfase em Letras, atuando principalmente nos seguintes temas: ensino de literatura, currículo, docência e gênero.

E-mail: edersoncruz.sl@gmail.com 